\title{
Migraine and tension-type headache triggers in a Greek population
}

\author{
Fatores desencadeantes de enxaqueca e de cefaleia tipo tensional em uma \\ população grega
}

Vasilios Constantinides, Evangelos Anagnostou, Anastasia Bougea, George Paraskevas, Elisavet Kapaki, loannis Evdokimidis, Evangelia Kararizou

\begin{abstract}
Migraine and tension type headache are the two most common primary headaches. The purpose of this study was to detect differences in clinical characteristics and headache triggers and in a Greek cohort of 51 migraineurs and 12 patients with tension-type headache. (TTH) Migraine patients had a significantly lower age at headache onset and frequency, higher mean visual analogue scale (VAS) and greater maximum duration of headache episodes compared to TTH patients. They did not differ from (TTH) patients in quality of headache, laterality of pain, way of headache installation and progression and temporal pattern of headaches. Nausea, vomiting and phonophobia were more frequent in migraine. Triggering of headaches by dietary factors was associated with migraine, whereas there was no difference between the two groups in any of the other headache triggers. Stress, both physical and psychological, were particularly common in both patient groups.
\end{abstract}

Keywords: migraine, tension type headache, precipitating factors.

\section{RESUMO}

Enxaqueca e cefaleia tipo tensional são as duas cefaleias primárias mais frequentes. 0 propósito deste estudo foi avaliar as diferenças e características dos fatores desencadeantes destas cefaleias numa coorte grega de 51 pacientes com enxaqueca e 12 com cefaleia tipo tensional. Pacientes com enxaqueca tinham uma idade significativamente menor por ocasião do início da cefaleia e maior frequência, maiores valores de (VAS) e maior duração dos episódios em comparação com os pacientes com (CTT). Não houve diferença entre os pacientes com enxaqueca e (CTT) com relação à qualidade e lateralidade da dor, na forma de instalação e progressão, e no padrão temporal das cefaleias. Náuseas, vômitos e fonofobia foram mais frequentes em enxaqueca. Fatores desencadeantes na dieta estavam associados à enxaqueca, enquanto não houve diferença entre os dois grupos para outros fatores desencadeantes. Estresse físico e psicológico foram particularmente prevalentes em ambos os grupos de pacientes.

Palavras-chave: enxaqueca, cefaleia tipo tensional, fatores desencadeantes.

Migraine is a primary headache that is usually severe, unilateral and throbbing in nature. It is often accompanied by photo - or phonophobia, nausea and vomiting and it worsens with physical activity ${ }^{1}$. A number of external and internal factors are considered triggers for migraine. Amongst them, the most common are stress, dietary factors, environmental factors, hormonal factors and sleep disorders.

Tension type headache on the other hand is the most common primary headache, and is characterized by bilateral location, pressing/tightening quality and of generally milder intensity compared to migraine. The accompanying symptoms of migraine (nausea, vomiting, photo- and phonophobia) are only rarely encountered in tension-type headache ${ }^{1}$.
The importance of these triggers (particularly stress and dietary factors) varies significantly among studies, presumably because of the different lifestyles and cultures of cohorts ${ }^{2,3,4,5}$.

The purpose of this article is to review the literature regarding trigger factors of headache and to present data about the prevalence of these trigger factors in a Greek cohort of migraineurs and patients with tension-type headache (TTH) in a Headache Clinic of a Tertiary Hospital in Athens.

\section{METHOD}

All patients examined at the Headache Clinic of Eginition Hospital during the period of 5/2011-5/2012 with a definite

Eginitio Hospital, Department of Neurology, Greece.

Correspondence: Vassilios Constantinides; Eginitio Hospital, Department of Neurology; Vassilisis Sofias 72-74, Athens Attica 11528, Greece;

E-mail:vassilis.kon@hotmail.com

Conflict of interest: There is no conflict of interest to declare.

Received 06 August 2014; Received in final form 27 March 2015; Accepted 15 April 2015. 
diagnosis of migraine without aura, migraine with aura or frequent episodic tension type headache, (according to the $2^{\text {nd }}$ edition of the International Classification of Headache Disorders) were included in the study ${ }^{1}$. The study was approved by the Ethics Committee of Eginition Hospital. All the procedures were in accordance with the ethical standards with the Helsinki Declaration of 1975, as revised in 1983 and our patients were informed about that. In order to exclude secondary headaches, all patients underwent a complete neurological examination, basic blood tests, and brain imaging with CT or MRI, as well as more specialized tests when it was considered appropriate.

Demographic (age, gender) and clinical data were recorded for all the patients. Clinical data included age at disease onset, mean headache frequency and duration, mean and maximum headache severity (based on a visual analogue scale), presence (or absence) of a specific temporal pattern (e.g. headaches in the morning, midday, afternoon or evening) and of attacks that awaken the patient, way of attack installation (sudden or progressive), quality (pulsating, pressing, stabbing or mixed) and localization of headache.

All patients were asked about any association of their headache with the consumption of specific dietary triggers (alcohol, cheese, chocolate, citrus fruits, bananas), sleep disorders (insomnia and/or hypersomnolence), menstruation, the presence of mental and physical stress and weather - temperature changes.

The treating physician reported a headache characteristic or trigger factor as present or absent, based on the patient's assessment during an interview. Although no formal questionnaires to quantify trigger characteristics were used, the questions were stereotyped.

All patients were furthermore asked about whether they considered that the recent financial crisis had affected them or not, without formal recording of the financial status of the patients. The Hamilton Anxiety Rating Scale (HAM-A) was administered, to objectively assess the anxiety levels of the patients.

Data on premonitory symptoms ( fatigue, difficulty concentrating, yawning, pallor, neck stiffness), aura, associated (photophobia, phonophobia, nausea, vomit, conjuctival injection, rhinorrhoea, eyelid edema, miosis - ptosis, facial sweating), relieving (sleep, local pressure, shower etc) and aggrevating factors (especially headache worsening with physical activity) were recorded.

Continuous data were analyzed by independent samples t-test and categorical data by $\mathrm{x}^{2}$ test.

\section{RESULTS}

Of the 207 patients examined, 63 patients met the criteria for definite migraine and tension-type headache. 39 (62\%) suffered from migraine without aura, 12 (19\%) from migraine with aura (19\%) and 12 (19\%) from tension-type headache.
Most of the remaining patients suffered from other primary or secondary headaches. Female/male ratio was 6:1, mean patient age was 40.7 years and mean age at headache onset was $22.8 \pm 0.9$ years. Patients had a mean VAS of $7.1 \pm 1.9$ (maximum VAS 9.6 \pm 0.8 ), mean days of headache per month $7.3 \pm 8.7$ episodes/month and mean headache episode duration of $25.4 \pm 36.9$ hours.

Migraine patients had a significantly lower age at headache onset, fewer days of headache per month, higher mean visual analogue scale (VAS) and greater maximum duration of headache episodes compared to TTH patients. The two groups did not differ in their age and in mean headache duration (Table 1).

Migraine patients did not differ from TTH patients in quality of headache, laterality of pain, way of headache installation and progression and temporal pattern of headaches. However, migraine presented more frequently in the retrobulbar/frontal region, whereas TTH mainly occurred in the temporal region (Table 1).

Regarding accompanying symptoms, nausea, vomiting and phonophobia differed significantly between the two groups (more frequent in migraine). Photophobia and the occurrence of vasomotor type disorders (eye redness - tearing - nasal congestion) did not differ between the two groups (Table 1).

Triggering of headaches by dietary factors (when asked as a general term) was associated with migraine $(\mathrm{p}=0.019)$. Alcohol was a more common headache trigger factor in migraine patients $(\mathrm{p}=0.044)$. However, the two groups did not differ when specific food items were analyzed separately (chocolate, cheese, citrus fruits, bananas). Sleep disorders, menstruation, changes in temperature/weather did not differ in the two groups. There were no differences between migraine and TTH patients in relieving and aggravating factors. Stress, both physical and psychological, was particularly common in both patient groups (Table 2). However, the two groups did not differ in their anxiety levels, as measured by the Hamilton Anxiety Rating Scale.

\section{DISCUSSION}

Our study revealed many of the known clinical differences of patients with migraine compared to $\mathrm{TTH}^{2,3,4,5,6,7}$.

Patients with migraine exhibited a lower age of headache onset, fewer days of headache per month, increased intensity and duration of headache, different localization of pain, greater frequency of nausea, vomiting and phonophobia. However, there was no difference in the laterality of pain, quality of pain and presence of photophobia between migraine and TTH, three characteristics that are considered established discriminators between the two headache types.

This could be attributed to the relatively small sample size of our study. Furthermore, some of these characteristics were divided in many categories (e.g. quality of headache), thus 


\begin{tabular}{|c|c|c|c|}
\hline & Migaine & Tension type headache & $\mathrm{p}$-value \\
\hline $\mathrm{N}$ & 51 & 12 & \\
\hline Age at headache onset & $21.2 \pm 10.4$ & $29.4 \pm 11.5$ & 0.019 \\
\hline Age & $41.4 \pm 12.9$ & $37.5 \pm 15.5$ & 0.429 \\
\hline Sex (male/female) & $8 / 43$ & $1 / 11$ & \\
\hline Frequency of headache episodes (per month) & $5.0 \pm 5.4$ & $17.1 \pm 12.1$ & 0.0001 \\
\hline Max episode duration (hours) & $67.6 \pm 65.5$ & $19.0 \pm 32.1$ & 0.045 \\
\hline Mean episode duration (hours) & $28.0 \pm 38.4$ & $10.4 \pm 23.3$ & 0.08 \\
\hline MaxVAS & $9.9 \pm 0.5$ & $9.0 \pm 1.3$ & 0.114 \\
\hline MeanVAS & $7.4 \pm 1.6$ & $5.5 \pm 2.2$ & 0.001 \\
\hline \multicolumn{4}{|l|}{ Quality of headache } \\
\hline Pulsating & 13 & 2 & \\
\hline Pressing & 5 & 2 & \\
\hline Stabbing & 11 & 7 & \\
\hline Pulsating + pressing & 14 & 1 & 0.237 \\
\hline Pulsating + stabbing & 2 & 0 & \\
\hline Pressing + stabbing & 2 & 0 & \\
\hline All 3 types & 2 & 0 & \\
\hline Laterality (unilateral/bilateral) & $27 / 22$ & $3 / 9$ & 0.062 \\
\hline \multicolumn{4}{|l|}{ Location } \\
\hline Retroorbital & 20 & 1 & \\
\hline Frontal & 17 & 3 & \\
\hline Parietal & 1 & 1 & 0.001 \\
\hline Temporal & 1 & 5 & \\
\hline Occipital & 7 & 2 & \\
\hline Diffuse & 5 & 0 & \\
\hline Nausea (yes/no) & $35 / 16$ & $4 / 8$ & 0.023 \\
\hline Vomitting (yes/no) & $18 / 33$ & $0 / 12$ & 0.015 \\
\hline Photosensitivity (yes/no) & $38 / 13$ & $7 / 5$ & 0.264 \\
\hline Sound sensitivity (yes/no) & $38 / 13$ & $4 / 8$ & 0.006 \\
\hline Hamilton Anxiety Rating Scale & $8.7 \pm 7.6$ & $11.4 \pm 7.8$ & 0.368 \\
\hline
\end{tabular}

VAS: visual analogue scale.

Table 2. Comparison of trigger factors between the 2 groups.

\begin{tabular}{lccc} 
& Migaine & $\begin{array}{c}\text { Tension type } \\
\text { headache }\end{array}$ & p-value \\
\hline Menses (yes/no) & $27 / 16$ & $5 / 6$ & 0.296 \\
Stress (yes/no) & $27 / 24$ & $8 / 4$ & 0.389 \\
Fatigue (yes/no) & $13 / 36$ & $3 / 9$ & 0.914 \\
Food (yes/no) & $17 / 34$ & $0 / 12$ & 0.019 \\
Alcohol (yes/no) & $13 / 36$ & $0 / 12$ & 0.044 \\
Chocolate (yes/no) & $5 / 44$ & $0 / 12$ & 0.248 \\
Cheese (yes/no) & $2 / 47$ & $0 / 12$ & 0.477 \\
Bananas (yes/no) & $1 / 48$ & $0 / 12$ & 0.618 \\
Insomnia (yes/no) & $19 / 32$ & $1 / 11$ & 0.053 \\
Hypersomnolence (yes/no) & $3 / 48$ & $1 / 11$ & 0.754 \\
Temperature (yes/no) & $10 / 41$ & $2 / 10$ & 0.815 \\
\hline
\end{tabular}

requiring a larger sample to reach statistical significance. A selection bias should also be taken into consideration, since the patients examined at a University hospital are likely to differ from the general population, representing more atypical, complex or difficult to treat cases.

Despite not reaching statistical significance, migraine patients exhibited a clear tendency towards more frequent unilateral, throbbing headaches with accompanying photosensitivity compared to TTH patients, as expected.

In terms of triggers, only dietary factors (as a group) and alcohol were associated with migraine in our study. This relationship is well established in the literature ${ }^{2,3}$. No other specific food item was a statistically significant trigger in our study, although again there was a clear tendency of more frequent report of chocolate as trigger in migraine patients.

Most studies support the relationship between migraine and alcohol consumption, which is considered a major trigger factor of migraine attacks $1,2,4,5,6,7,8,9,10,11,12,13,14,15,16,17,18,19,20,21$. However this relationship is complex and depends on many factors. The type of beverage is of some importance. Most studies consider red wine to be the most important migraine trigger ${ }^{2,9,12}$. Other studies however disagree ${ }^{5,11}$. The importance of white wine and beer is controversial ${ }^{9,10,11,12,18,22}$. Milde-Bush et al. report the importance of cocktails as a triggering factor for both migraine and $\mathrm{TTH}^{23}$. Aaamodt et al. reported a decrease in migraine attacks with an increase of alcohol consumption ${ }^{24}$.

Alcohol consumption was a trigger in $27 \%$ of the migraineurs in our study, in agreement with the literature, but 
did not relate with tension-type headache. Red wine was the commonest trigger. Beer and cocktails did not relate to migraine attacks.

Insomnia was a relatively common migraine trigger (19 out of 51 patients) in our study. However, only 1 of 12 patients with tension-type headache reported insomnia as a trigger. This difference was important, but did not reach statistical significance $(\mathrm{p}=0.053)$.

Sleep disturbances have been extensively studied and seem to be of some importance in both migraine and TTH. Bruni et al. reported that poor sleep quality was the commonest headache trigger (migraine or not) ${ }^{25}$. Kelman et al. also reported a high frequency of sleep disturbances in migraineurs (difficulty in sleep initiation and maintenance, reduction of total sleep hours ${ }^{26}$. Bruni et al. concluded that improvement of sleep quality resulted in a reduction of migraine attack severity and frequency ${ }^{27}$.

Stress did not differ between migraine and TTH patients in our study (as measured by HAM-A), despite the fact that stress is considered a traditional migraine trigger. However, 27 out of 51 patients with migraine and 8 out of 12 with tension type headache considered stress to be an important headache trigger. These results emphasize the importance of stress in both migraine and TTH.

The recent financial crisis in Greece could play a part in the elevated levels of stress in both study groups. Although the majority of patients reported that they were affected by the financial crisis, we did not include a formal questionnaire to assess the possible interaction between the financial crisis, stress and the occurrence of headache. A currently ongoing study in our clinic is specifically designed to answer this complex interaction.

Zivadinov et al. reported that contrary to widespread belief, stress was a more common trigger factor in migraineurs and physical activity in TTH. Other frequent precipitating factors included frequent travels and changes in weather conditions. Migraine with aura (MA) correlated with frequent travelling, dietary factors and weather conditions, compared to migraine without aura (MWA $)^{2}$.

Another population based study in Iraq, reached the conclusion that psychological upset, physical activity and changes in weather conditions were the most important precipitating factors in migraine patients ${ }^{28}$. The results of a study by Theeler et al. on a mainly military population with headache were similar to the previous studies. Environmental factors, stress, dietary factors and fatigue were the most common headache triggers ${ }^{3}$.

Hansen et al. reached similar conclusions in their study of trigger factors in patients with familial hemiplegic migraine. Stress, intense light, emotional turmoil and increased or decreased sleeping hours were the most often reported trigger factors ${ }^{29}$.
Another cross-sectional study by Camboim et al. considered stress, environmental and hormonal factors to be the most important trigger factors for a migraine attack. The majority of patients reported susceptibility to a multitude of trigger factors $(>5)^{30}$.

Our study is in agreement with the literature in regard to the most common migraine triggers such as dietary factors, alcohol and sleep. We could not establish any difference between TTH and migraine patients in the frequency of specific food items consumption and stress, which are also considered classic migraine triggers.

Some differences between the two study groups were important but did not reach a level of statistical significance. This could be attributed to the relatively small sample size of our study. This is supported by the clear tendency towards more frequent occurrence of menses and chocolate in migraine patients compared to TTH patients, factors that are well established migraine triggers.

All trigger factors were based on the patient's assessment during an interview. We did not include quantitative data regarding the frequency and severity of the triggers. Thus it is conceivable, that although TTH and migraine patients in our study did not differ in the frequency of some triggers, they might differ in their clinical importance (e.g. severity).

Our study population is not representative of the general population, because patients who refer to a university hospital tend to have more severe, atypical or difficult to treat symptoms. Thus a selection bias cannot be excluded. However it is important to present data on the cohorts that are examined in hospital environments, to highlight the differences with population-based data.

Despite these shortcomings, data recorded systematically in a hospital environment by trained physicians are more robust than data from cross-sectional population studies and diagnosis accuracy is significantly improved in a clinical environment compared to data from self-administered questionnaires.

Most data on the subject derive from cross-sectional population or retrospective studies. Study populations, inclusion criteria, study design and methodology vary considerably, prohibiting safe conclusions on the subject.

Ideally, a population based study, with data collected by trained physicians would provide concrete data on the subject of triggers of primary headaches. These data would be relevant in a clinical level, aiding differential diagnosis of primary headaches and promoting avoidance behavior as part of headache treatment. Furthermore, it would help elucidate the pathophysiological mechanisms underlying each primary headache, thus promoting more targeted therapies of these difficult to treat conditions. 


\section{References}

1. The International Classification of Headache Disorders 2 nd edition. Cephalalgia. 2004;24(1 Suppl):9-160.

2. Zivadinov R, Willheim K, Sepic-Grahovac D, Jurjevic A, Bucuk $\mathrm{M}$, Brnabic-Razmilic $\mathrm{O}$ et al. Migraine and tension-type headache in Croatia: a population-based survey of precipitating factors. Cephalalgia. 2003;23(5):336-43. http://dx.doi.org/10.1046/j.1468-2982.2003.00544.x

3. Theeler BJ, Kenney K, Prokhorenko OA, Fideli US, Campbell W, Erickson JC. Headache triggers in the US military. Headache. 2010;50(5):790-4. http://dx.doi.org/10.1111/j.1526-4610.2009.01571.x

4. Aamodt AH, Stovner LJ, Hagen K, Bråthen G, Zwart J. Headache prevalence related to smoking and alcohol use. The Head-HUNT Study. Eur J Neurol. 2006;13(11):1233-38. http://dx.doi.org/10.1111/j.1468-1331.2006.01492.x

5. Takeshima T, Ishizaki K, Fukuhara Y, Ijiri T, Kusumi M, Walutani $Y$ et al. Population-based door-to-door survey of migraine in Japan: the Daisen study. Headache. 2004;44(1):8-19. http://dx.doi.org/10.1111/j.1526-4610.2004.04004.x

6. Henry P, Auray JP, Gaudin AF, Dartigues JF, Duru G, Lantéri-Minet $M$ et al. Prevalence and clinical characteristics of migraine in France. Neurology. 2002;59(2):232-7. http://dx.doi.org/10.1212/WNL.59.2.232

7. Ulrich V, Olesen J, Gervil M, Russell MB. Possible risk factors and precipitants for migraine with aura in discordant twin-pairs: a population-based study. Cephalalgia. 2000;20(9):821-5. http://dx.doi.org/10.1046/j.1468-2982.2000.00135.x

8. BánkJ, Márton S. Hungarian migraine epidemiology. Headache. 2000;40(2):164-9. http://dx.doi.org/10.1046/j.1526-4610.2000.00023.x

9. Ulrich V, Russell MB, Jensen R, Olesen J. A comparison of tension-type headache in migraineurs and in non-migraineurs: a population-based study. Pain. 1996;67(2-3):501-6. http://dx.doi.org/10.1016/0304-3959(96)03164-8

10. Rasmussen BK. Migraine and tension-type headache in a general population: precipitating factors, female hormones, sleep pattern and relation to lifestyle. Pain. 1993;53(1):65-72. http://dx.doi.org/10.1016/0304-3959(93)90057-V

11. Yadav RK, Kalita J, Misra UK. A study of triggers of migraine in India. Pain Med. 2010;11(1):44-47. http://dx.doi.org/10.1111/j.1526-4637.2009.00725.x

12. Fukui PT, Gonçalves TR, Strabelli CG, Lucchino NM, Matos FC, Santos JP et al. Trigger factors in migraine patients. Arq Neuropsiquiatr. 2008;66(3A):494-9. http://dx.doi.org/10.1590/S0004-282X2008000400011

13. Kelman $\mathrm{L}$. The triggers or precipitants of the acute migraine attack. Cephalalgia. 2007;27(5):394-402. http://dx.doi.org/10.1111/j.1468-2982.2007.01303.x

14. Wöber C, Holzhammer J, Zeitlhofer J, Wessely P, Wöber-Bingöl C. Trigger factors of migraine and tension-type headache: experience and knowledge of the patients.J Headache Pain. 2006;7(4):188-95. http://dx.doi.org/10.1007/s10194-006-0305-3

15. Karli N, Zarifoglu M, Calisir N, Akgoz S. Comparison of pre-headache phases and trigger factors of migraine and episodic tension-type headache: do they share similar clinical pathophysiology? Cephalalgia. 2005;25(6):444-51. http://dx.doi.org/10.1111/j.1468-2982.2005.00880.x

16. Ierusalimschy R, Moreira Filho PF. [Precipitating factors of migraine attacks in patients with migraine without aura]. Arq Neuropsiquiatr. 2002;60(3-A):609-13. Portuguese. http://dx.doi.org/10.1590/S0004-282X2002000400017

17. Spierings $E L$, Ranke AH, Honkoop PC. Precipitating and aggravating factors of migraine versus tension-type headache. Headache. 2001;41 (6):554-8. http://dx.doi.org/10.1046/j.1526-4610.2001.041006554.x

18. Peatfield RC. Relationships between food, wine, and beer-precipitated migrainous headaches. Headache. 1995;35(6):355-7. http://dx.doi.org/10.1111/j.1526-4610.1995.hed3506355.x

19. Van den Bergh V, Amery WK, Waelkens J. Trigger factors in migraine: a study conducted by the Belgian Migraine Society. Headache. 1987;27(4):191-6. http://dx.doi.org/10.1111/j.1526-4610.1987.hed2704191.x

20. Wöber C, Brannath W, Schmidt K, Kapitan M, Rudel E, Wessely $P$ et al. Prospective analysis of factors related to migraine attacks: the PAMINA study. Cephalalgia. 2007;27(4):304-14. http://dx.doi.org/10.1111/j.1468-2982.2007.01279.x

21. Littlewood JT, Gibb C, Glover V, Sandler M, Davies PT, Rose FC. Red wine as a cause of migraine. Lancet. 1988;1(8585):558-59. http://dx.doi.org/10.1016/S0140-6736(88)91353-0

22. Turner LC, Molgaard CA, Gardner CH, Rothrock JF, Stang PE. Migraine trigger factors in non-clinical Mexican-American population in San Diego county: implications for etiology. Cephalalgia. 1995;15(6):523-30. http://dx.doi.org/10.1046/j.1468-2982.1995.1506523.x

23. Milde-Busch A, Blaschek A, Borggräfe I, Heinen F, Straube A, von Kries R Associations of diet and lifestyle with headache in high-school students: results from a cross-sectional study. Headache. 2010;50(7):1104-14. http://dx.doi.org/10.1111/j.1526-4610.2010.01706.x

24. Robbins L. Precipitating factors in migraine: a retrospective review of 494 patients. Headache. 1994;34(4):214-6. http://dx.doi.org/10.1111/j.1526-4610.1994.hed3404214.x

25. Bruni O, Russo PM, Ferri R, Novelli L, Galli F, Guidetti V. Relationships between headache and sleep in a non-clinical population of children and adolescents. Sleep Med. 2008;9(5):542-8. http://dx.doi.org/10.1016/j.sleep.2007.08.010

26. Kelman L, Rains JC. Headache and sleep: examination of sleep patterns and complaints in a large clinical sample of migraineurs. Headache. 2005;45(7):904-10. http://dx.doi.org/10.1111/j.1526-4610.2005.05159.x

27. Bruni O, Galli F, Guidetti V. Sleep hygiene and migraine in children and adolescents. Cephalalgia. 1999;19 Suppl 25:57-9.

28. Al-Shimmery EK. Precipitating and relieving factors of migraine headache in 200 iraqi kurdish patients. Oman Med J. 2010;25(3):212-7. http://dx.doi.org/10.5001/omj.2010.59

29. Hansen JM, Hauge AW, Ashina M, Olesen J. Trigger factors for familial hemiplegic migraine. Cephalalgia. 2011;31(12):1274-81. http://dx.doi.org/10.1177/0333102411415878

30. Camboim Rockett F, Castro K, Rossoni de Oliveira V, da Silveira Perla A, Fagundes Chaves ML, Schweigert Perry ID. Perceived migraine triggers: do dietary factors play a role? Nutr Hosp. 2012;27(2):483-9. 